Review

\title{
Lipid Emulsion for Treating Local Anesthetic Systemic Toxicity
}

\author{
Seong-Ho Ok ${ }^{1,2^{*}}$, Jeong-Min Hong ${ }^{3^{*}}$, Soo Hee Lee ${ }^{1,2}$ and Ju-Tae Sohn ${ }^{1,2 \bowtie}$ \\ 1. Department of Anesthesiology and Pain Medicine, Gyeongsang National University School of Medicine, Gyeongsang National University Hospital, 15 \\ Jinju-daero 816 Beon-gil, Jinju-si, Gyeongsangnam-do, 52727, Republic of Korea \\ 2. Institute of Health Sciences, Gyeongsang National University, Jinju-si, 52727, Republic of Korea \\ 3. Department of Anesthesia and Pain Medicine, Pusan National University School of Medicine, Pusan National University Hospital, Busan, Republic of Korea \\ *These authors equally contributed to this study as co-first authors. \\ $\triangle$ Corresponding author: Ju-Tae Sohn, Department of Anesthesiology and Pain Medicine, Gyeongsang National University Hospital, 79 Gangnam-ro, Jinju-si, \\ Gyeongsangnam-do, 52727, Republic of Korea; Tel.: +82-55-750-8586; Fax: +82-55-750-8142; E-mail: jtsohn@gnu.ac.kr \\ (C) Ivyspring International Publisher. This is an open access article distributed under the terms of the Creative Commons Attribution (CC BY-NC) license \\ (https://creativecommons.org/licenses/by-nc/4.0/). See http://ivyspring.com/terms for full terms and conditions.
}

Received: 2017.09.01; Accepted: 2018.04.12; Published: 2018.05.14

\begin{abstract}
Lipid emulsion has been shown to be an effective treatment for systemic toxicity induced by local anesthetics, which is reflected in case reports. A systemic review and meta-analysis confirm the efficacy of this treatment. Investigators have suggested mechanisms associated with the lipid emulsion-mediated recovery of cardiovascular collapse caused by local anesthetic systemic toxicity; these mechanisms include lipid sink, a widely accepted theory in which highly soluble local anesthetics (particularly bupivacaine) are absorbed into the lipid phase of plasma from tissues (e.g., the heart) affected by local-anesthetic-induced toxicity; enhanced redistribution (lipid shuttle); fatty acid supply; reversal of mitochondrial dysfunction; inotropic effects; glycogen synthase kinase-3 $\beta$ phosphorylation associated with inhibition of the mitochondrial permeability transition pore opening; inhibition of nitric oxide release; and reversal of cardiac sodium channel blockade. The current review includes the following: 1) an introduction, 2) a list of the proposed mechanisms, 3) a discussion of the best lipid emulsion treatment for reversal of local anesthetic toxicity, 4) a description of the effect of epinephrine on lipid emulsion-mediated resuscitation, 5) a description of the recommended lipid emulsion treatment, and 6) a conclusion.
\end{abstract}

Key words: lipid emulsion, local anesthetic systemic toxicity, lipid sink, lipid shuttle, bupivacaine

\section{Introduction}

Lipid emulsion was originally developed for parenteral nutrition in the 1960s [1]. However, lipid emulsion is currently used to treat local anesthetic-induced systemic toxicity [2-6]. Carnitine helps transport long-chain fatty acids into the mitochondria [7-9]; carnitine-acylcarnitine translocase transports long-chain acyl-carnitine into the mitochondrial matrix and returns carnitine to the cytoplasm [9]. $\beta$-Oxidation produces adenosine triphosphate (ATP) in cardiac mitochondria using long-chain fatty acids as the major energy source of the heart [9]. Bupivacaine prevents long-chain fatty acid transport to the mitochondria by inhibiting carnitine-acylcarnitine translocase [8-10]. Pretreatm- ent with L-carnitine before bupivacaine-induced asystole in rats decreased the susceptibility to bupivacaine-induced cardiac toxicity [11]. In 1997, Weinberg et al. reported that subcutaneous injection of a small dose of bupivacaine (non-toxic dose: $22 \mathrm{mg}$ ) in a 16-year-old female patient with isovaleric acidemia yielded unexpected ventricular arrhythmia likely caused by secondary systemic carnitine deficiency [7]. Based on these reports, this unexpected ventricular arrhythmia was likely associated with increased susceptibility to bupivacaine toxicity due to carnitine deficiency [7-11]. In addition, Wong et al. reported ventricular arrhythmia caused by the presumed intravascular migration of an epidural 
catheter in a 6-year-old male patient with both secondary carnitine deficiency due to long-term treatment with valproic acid and a non-toxic dose of bupivacaine $(0.58 \mathrm{mg} / \mathrm{ml})$ [12]. Pretreatment with lipid emulsion reportedly increased the dosage of bupivacaine needed to produce asystole in rats, and a mixture of Intralipid ${ }^{\circledR}$ and plasma containing bupivacaine produced a high lipid-to-aqueous-phase ratio of bupivacaine (11.9 \pm 1.77$)$, suggesting that Intralipid® has a high capacity to bind bupivacaine [13]. Moreover, Intralipid ${ }^{\circledR}$ improved the survival and hemodynamics of bupivacaine-induced cardiac toxicity in dogs [14]. The administration of lipid emulsion affected the central nervous system toxicity induced by local anesthetics by increasing the dosage of bupivacaine and levobupivacaine needed to produce convulsion in awake rats [15]. Rosenblatt et al. reported the first clinical case of lipid emulsion for treating presumed bupivacaine toxicity in 2006 [16]. The treated patient, a 58-year-old male with seizure and asystole due to toxicity from bupivacaine and mepivacaine used in an interscalene brachial plexus block, was unresponsive to advanced cardiac life support, but lipid emulsion led to recovery [16]. Moreover, the first clinical case of lipid emulsion resuscitation of a patient with toxicity induced by a non-local anesthetic drug was reported in 2008: Intralipid ${ }^{\circledR}$ infusion led to the recovery of a 17-year-old female patient with severe cardiovascular depression and seizure due to toxic doses of bupropion and lamotrigine [17]. According to reviews of many clinical case reports and laboratory studies, lipid emulsion can effectively treat cardiovascular collapse caused by a toxic dose of local anesthetics [2-5]. Specifically, toxicity of bupivacaine among local anesthetics is most amenable to lipid emulsion treatment [2-4].

\section{Proposed mechanisms}

The widely accepted lipid sink theory proposes a mechanism responsible for lipid emulsion-mediated resuscitation in cases of systemic toxicity induced by local anesthetics. This theory states that highly lipid-soluble drugs, including local anesthetics and non-local anesthetic drugs, are absorbed into the lipid emulsion of the plasma and removed from tissues affected by toxicity [6]. Lipid emulsion (Intralipid ${ }^{\circledR}$ ) enhanced bupivacaine removal from cardiac tissues following bupivacaine (a highly lipid-soluble local anesthetic)-induced asystole in isolated rat hearts and did so with improved hemodynamics [18]. Pretreatment with Intralipid( ${ }^{\circledR}$ increased the lethal dose in rats and enhanced the total bupivacaine concentration of the lipid emulsion in plasma during asystole [13]. Moreover, Intralipid® improved the rate pressure product during resuscitation of bupivacaine-induced asystole in isolated rat hearts using the Langendorff preparation [19]. In this study, lipid emulsion produced both a concomitant reduction in myocardial bupivacaine in a concentration-dependent manner and a better early response than late response during recovery [19]. Pretreatment with lipid emulsion increased the time required to produce bupivacaine-induced asystole, and post-treatment with lipid emulsion shortened the recovery time from bupivacaine-induced cardiac arrest in a Langendorff isolated rat heart model $[20,21]$. In contrast, pretreatment with lipid emulsion did not significantly alter the time required to produce mepivacaine-induced asystole, and post-treatment with lipid emulsion had no effect on the recovery time from ropivacaine-and-mepivacaineinduced cardiac arrest [20,21]. Although posttreatment with lipid emulsion in an isolated Langendorff heart model has several limitations, including the use of a buffer solution with only lipid emulsion and no local anesthetics, these results support the lipid sink theory [20-22]. Considering the lipid solubility of local anesthetics (log [octanol/ buffer partition coefficient] at $\mathrm{pH} 7.4$; bupivacaine [2.539], ropivacaine [2.060], lidocaine [1.633] and mepivacaine [1.322]), these previous reports indicate a relatively high sequestration of the highly lipidsoluble local anesthetic bupivacaine by lipid emulsion $[13,14,18-21,23]$. Intralipid ${ }^{\circledR}$ accelerated the recovery of contractility in stimulated myocardial contraction in a guinea pig model, with a reduction in the myocardial bupivacaine content from a toxic dose causing asystole [24]. In another study, lipid emulsion decreased the plasma concentration of the drug, with a higher lipid solubility or a larger distribution volume [25]. Lipid emulsion attenuated bupivacaineand mepivacaine-induced inhibition of fast $\mathrm{Na}+$ currents in adult rat ventricular myocytes [26]. In addition, an aqueous-phase solution containing bupivacaine (without lipid emulsion) obtained through ultracentrifugation attenuated the blockade of the fast $\mathrm{Na}+$ current compared with that of the fast $\mathrm{Na}+$ current induced by bupivacaine alone [26]. Bupivacaine promoted the lipid emulsionmediated reversal of the fast $\mathrm{Na}+$ current blockade better than mepivacaine [26]. Other in vitro studies have investigated the binding of lipid emulsions to local anesthetics and support the lipid sink theory $[23,27,28]$. The binding capacity of lipid emulsion (Intralipid $\AA$ and Medialipid ${ }^{\circledR}$ ) to bupivacaine was found to be higher than that to ropivacaine, and the magnitude of the lipid emulsion-mediated reduction in serum concentration of local anesthetics was reportedly positively correlated with the lipid 
solubility of local anesthetics (bupivacaine > ropivacaine $>$ mepivacaine) $[23,27,28]$. A toxic dose of local anesthetics, including bupivacaine, levobupivacaine, ropivacaine, lidocaine and mepivacaine, produced severe vasodilation in isolated endotheliumdenuded rat aorta pre-contracted with the tyrosine phosphatase inhibitor sodium orthovanadate or the voltage-operated calcium channel activator $\mathrm{KCl}(60$ $\mathrm{mM}$ ) [29-31]. In contrast, lipid emulsion (Intralipid ${ }^{\circ}$, SMOFlipid ${ }^{\circledR}$ and Lipofundin ${ }^{\circledR}$ MCT/LCT) reversed the toxic dose of local anesthetic-induced vasodilation in a lipid solubility-dependent manner for local anesthetics (bupivacaine $>$ ropivacaine $>$ lidocaine $>$ mepivacaine) [23,29-31]. In isolated endotheliumdenuded rat aorta pre-contracted with the protein kinase $C$ activator phorbol 12,13-dibutyrate or the Rho-kinase activator NaF, lipid emulsion (Intralipid( $\left.{ }^{\circledR}\right)$ attenuated bupivacaine-induced vasodilation [32,33]. In contrast, lipid emulsion had no effect on mepivacaine-induced vasodilation [32,33]. SMOFlipid ${ }^{\circledR}$ enhanced the norepinephrine-mediated reversal of vasodilation induced by a toxic dose of local anesthetic in a lipid solubility-dependent manner [34]. Similar to previous reports that focused on cardiac arrest and depression induced by a toxic dose of bupivacaine, all lipid emulsion-mediated reversals or inhibitions of severe vasodilation induced by toxic doses of local anesthetic of isolated aorta observed in these previous studies were positively correlated with the lipid solubility of local anesthetics $[13,18-21,23,24,29-34]$. These previous reports suggest that lipid emulsion-mediated reversal or inhibition helps to mitigate the severe vasodilation (vascular collapse) induced by toxic doses of local anesthetics [29-34]. The magnitude of lipid emulsion (SMOFlipid $囚$ )-mediated attenuation of apoptosis induced by toxic doses of local anesthetics was higher for bupivacaine than for mepivacaine [35]. This study suggests that the inhibition of apoptosis induced by lipid emulsion was associated with the lipid solubility of local anesthetics [23,35]. Based on a physiologically-based pharmacokinetic model, lipid emulsion produced an only $11 \%$ reduction in the bupivacaine concentration in the heart within $3 \mathrm{~min}$ following lipid emulsion treatment and an $18 \%$ reduction in the bupivacaine concentration in the brain within $15 \mathrm{~min}$ [36]. Moreover, although a non-toxic dose of bupivacaine infusion in humans was used in a previous study, free bupivacaine concentrations did not significantly differ between the lipid emulsion and control groups [37]. However, the context-sensitive half-life of the total plasma bupivacaine concentration reportedly decreased in the lipid emulsion group, suggesting an enhanced distribution of bupivacaine throughout the tissue [37].
Lipid emulsion decreased the elimination half-life of bupivacaine and increased the initial bupivacaine content in the liver [38]. Lipid emulsion decreased the organ-to-blood ratio of bupivacaine in the cerebellum, frontal lobe, kidney and lung and enhanced the redistribution of bupivacaine into the liver [39]. Oher studies showed that lipid emulsion had no effect on the subjective symptoms induced by the central nervous system toxicity of lidocaine or the onset time of early signs associated with central nervous system toxicity induced by local anesthetics (ropivacaine and levobupivacaine) [40,41]. However, lipid emulsion decreased the mean area under unentrapped lidocaine concentration-time curves and peak local anesthetic concentration [40,41]. Lipid emulsion decreased the bispectral index but did not affect the duration of anesthesia [42]. These previous studies suggest that lipid emulsion can contribute to enhanced redistribution of local anesthetics or enhanced delivery of local anesthetics into the liver, which has been described as a lipid shuttle or subway [36-43]. Furthermore, lipid emulsion could reportedly mitigate the cardiovascular depression induced by toxic doses of local anesthetics (e.g., ropivacaine, lidocaine and mepivacaine) other than bupivacaine, with a relatively lower lipid solubility than that of bupivacaine [23,44-48]. These results suggest that mechanisms (e.g., lipid shuttle) other than lipid sink partially contribute to lipid emulsion-mediated resuscitation [44-48]. Thus, lipid sink and shuttle associated with the capture and redistribution of local anesthetics could concomitantly contribute to the lipid emulsion-mediated recovery of local anesthetic toxicity.

Local anesthetics, including bupivacaine, ropivacaine and lidocaine, inhibited carnitinestimulated pyruvate oxidation in cardiac mitochondria through the inhibition of carnitine-acylcarnitine translocase [10]. Fatty acid oxidation provided by lipid emulsion contributed to recovery from bupivacaine-induced cardiac depression in rats [49]. Furthermore, pretreatment with ATP abolished the myocardial depression induced by bupivacaine in an isolated rabbit right atrial model [50]. Lipid emulsion attenuated apoptosis induced by toxic doses of bupivacaine through inhibition of the bupivacaineinduced enhanced oxidative stress and mitochondrial dysfunction in H9c2 rat cardiomyoblasts [51,52]. These results appear to be associated with inhibition of the mitochondrial permeability transition pore opening [51,52]. These previous reports suggest that lipid emulsion-mediated recovery from bupivacaineinduced cardiac toxicity was associated with the reversal of the reduced fatty acid supply and ATP production or the mitochondrial dysfunction induced 
by toxic doses of bupivacaine [49-52]. In another study, lipid emulsion enhanced the mitochondrial respiratory function of myocardial cells and produced slight bupivacaine entrapment in bupivacaineinduced cardiac depression of pigs [53]. However, lipid emulsion did not improve the bupivacaineinduced decreased cardiac index [53].

Fettiplace et al. reported that Intralipid ${ }^{\circledR}$ increased the arterial pressure of rats and enhanced the rate of intraventricular pressure increases or decreases in an isolated rat heart model [54]. Lipid emulsion (Intralipid ${ }^{\circledR}$ and Lipofundin ${ }^{\circledR}$ MCT/LCT) increased the intracellular calcium level in H9c2 rat cardiomyoblasts [55]. Moreover, Intralipid ${ }^{\circledR}$ reversed the decreased left ventricular systolic pressure resulting from levobupivacaine-induced myocardial depression of isolated rat hearts using the Langendorff preparation [56]. These previous studies suggest that lipid emulsion has an intrinsic inotropic effect on the heart, with or without levobupivacaineinduced myocardial depression [54-56].

Postischemic reperfusion with lipid emulsion attenuated ischemia/reperfusion injury of the heart through the downstream kinase glycogen synthase kinase-3 $\beta$ (GSK-3 $\beta$ ) phosphorylation mediated by upstream kinases, including either phosphoinositide 3-kinase (PI3K) and Akt or extracellular signal-regulated kinase [57]. This cellular signaling pathway led to the inhibition of the mitochondrial permeability transition pore opening [57]. Intralipid $₫$-mediated resuscitation from bupivacaineinduced cardiac arrest in rats involves the activation of pathways associated with delta-opioid receptor and GSK-3 $\beta$ phosphorylation [58]. Bupivacaine toxicity induced phosphorylation of 5-adenosine monophosphate-activated protein kinase (AMPK) and inhibited Akt phosphorylation, which led to decreased activation of downstream kinases of mammalian target of rapamycin complex 1 [59]. However, in the presence of bupivacaine toxicity, lipid emulsion independently induced Akt phosphorylation without alteration of AMPK activation [59]. Lipid emulsion (Intralipid ${ }^{\circledR}$ ) attenuated the apoptosis induced by toxic doses of bupivacaine or the calcium channel blocker verapamil in H9c2 rat cardiomyoblasts through a pathway involving either PI3K, Akt and GSK-3 $\beta$ or delta-opioid receptors, PI3K and Akt, respectively $[60,61]$. Taken together, these reports suggest that the cellular signaling pathway downstream of Akt activated by lipid emulsion is associated with lipid emulsion-mediated recovery of bupivacaine toxicity [57-59].

Lipid emulsion attenuated acetylcholineinduced nitric oxide-mediated relaxation in isolated endothelium-intact rat aorta through inhibition of the nitric oxide-producing cellular signaling pathway proximal to guanylyl cyclase activation [62]. Local anesthetics, including levobupivacaine, ropivacaine and mepivacaine, caused vasoconstriction at lower doses and attenuated vasoconstriction (vasodilation) at higher doses in isolated rat aortas [63-65]. Local anesthetic-induced vasoconstriction was attenuated through endothelial nitric oxide production in endothelium-intact aortas compared with endothelium-denuded aortas [63-65]. Lipid emulsion reversed toxic doses of levobupivacaine-induced vasodilation through decreased nitric oxide bioavailability mediated by decreased caveolin-1 phosphorylation and reactive oxygen species $[31,66]$. Furthermore, Intralipid ${ }^{\circledR}$ alone increased left ventricular systolic pressure in an in vivo rat model [67]. However, pretreatment with the nitric oxide synthase inhibitor $\mathrm{NW}^{\mathrm{W}}$-nitro-L-arginine methyl ester abolished the Intralipid ${ }^{\circledR}$-mediated increase in left ventricular systolic pressure [67]. Considering previous reports, the lipid emulsion-mediated decreased bioavailability of nitric oxide released by toxic doses of local anesthetics may have partially contributed to the lipid emulsion-mediated reversal of vascular collapse from toxic doses of local anesthetic [31,62-67]. Intralipid ${ }^{\circledR}$ facilitated recovery from cardiovascular depression induced by bupivacaine in pigs through increased systemic vascular resistance [53]. Moreover, in a human study, Intralipid ${ }^{\circledR}$ increased blood pressure and systemic vascular resistance and decreased vascular compliance [68]. Considering previous reports, the increased systemic vascular resistance induced by lipid emulsion observed in previous studies involving humans and pigs may have been due to lipid emulsion-mediated inhibition of endothelial nitric oxide [53,62,67,68]. Mixed medium- and long-chain triglycerides reportedly increased systemic vascular resistance and decreased ventricular performance in awake dogs, whereas long-chain triglycerides alone did not significantly change systemic vascular resistance [69]. The Lipofundin ${ }^{\circledR}$ MCT/LCT-mediated inhibition of acetylcholine-induced nitric oxide-promoted relaxation was greater than Intralipid( ${ }^{\circledR}$-mediated inhibition; therefore, the abovementioned previously reported results may have been due to mixed medium- and long-chain triglyceride-mediated enhanced inhibition of nitric oxide-induced relaxation compared with long-chain triglycerides alone $[62,69]$. Compared with normal $\mathrm{pH}$ values (7.4), mild acidification ( $\mathrm{pH}$ 7.2) enhanced the lipid emulsion-mediated reversal of vasodilation induced by toxic doses of levobupivacaine, which is associated with lipid emulsion-induced inhibition of acidification-induced enhanced nitric oxide release 
[70]. In a study of acidification-mediated changes in the lipid emulsion's affinity for local anesthetics, acidification $(\mathrm{pH}$ 6.9) in human serum caused no significant change in the lipid emulsion-induced reduction in bupivacaine concentration [28]. However, acidification ( $\mathrm{pH}$ 7.0) in buffer decreased the affinity of lipid emulsion to bupivacaine by 1.68-fold [27]. The clinical cardiovascular collapse induced by toxic doses of local anesthetics is followed by metabolic and respiratory acidosis, which leads to increased levels of free (not protein bound) and ionized local anesthetics [71,72]. Thus, further study is needed to investigate the in vivo effect of acidosis on lipid emulsion-mediated resuscitation on the cardiovascular collapse induced by toxic doses of local anesthetic.

Lipofundin ${ }^{\circledR}$ MCT/LCT reduced the availability of cardiac sodium channels (Nav1.5) in human embryonic kidney (HEK)-293 cells expressing Nav1.5, whereas Intralipid ${ }^{\circledR}$ and Lipofundin ${ }^{\circledR}$ MCT/LCT partially reversed the blockade of bupivacaineinduced cardiac sodium channels [73]. The polyunsaturated fatty acid linolenic acid (18:3n-3) and the saturated fatty acid stearic acid (18:0), both of which are found in Intralipid $®$, attenuated the sodium current in HEK-293 cells expressing human cardiac sodium channels [74]. They also reversed the bupivacaine-induced sodium channel blockade in HEK-293 cells [74]. These results suggest that the fatty acids contained in lipid emulsion may modulate the cardiac sodium channel inhibited by local anesthetics through direct or indirect action [73-75].

In summary, although the lipid sink and shuttle mechanism is widely considered responsible for lipid emulsion resuscitation, the abovementioned mechanisms, including fatty acid supply, reversal of mitochondrial dysfunction, inotropic effect, GSK-3 $\beta$ phosphorylation, inhibition of nitric oxide release and reversal of cardiac sodium channel blockade, seem to be collectively involved in the resuscitation of cardiovascular collapse induced by toxic doses of local anesthetics [6]. Thus, it is very difficult to completely separate each individual proposed mechanism. For example, it is difficult to disentangle lipid emulsion-mediated reversal of mitochondrial dysfunction, cardiac sodium channel blockade and apoptosis from lipid sink and shuttle. The major free fatty acids involved in each of the proposed mechanisms responsible for the lipid emulsion-mediated resuscitation of local anesthetic systemic toxicity have not yet been determined. This information may be helpful for developing a specific lipid emulsion as an antidote for local anesthetic systemic toxicity.

\section{What is the best lipid emulsion for reversal of local anesthetic toxicity?}

Intralipid ${ }^{\circledR} 20 \%$ and Lipovenoes ${ }^{\circledR} 20 \%$ contain $100 \%$ long-chain triglycerides made from soybean oil [76,77]. The long-chain fatty acids contained in Intralipid ${ }^{\circledR}$ include $53 \%$ linoleic acid, $24 \%$ oleic acid, $11 \%$ palmitic acid, $8 \%$ alpha-linolenic acid and $4 \%$ stearic acid [76]. Lipofundin ${ }^{\circledR}$ MCT/LCT 20\% and Medialipid® ${ }^{\circledR} 20 \%$ contain $50 \%$ medium-chain triglycerides made from coconut oil and 50\% long-chain triglycerides made from soybean oil [76]. The medium-chain fatty acids contained in Lipofundin ${ }^{\circledR}$ MCT/LCT $20 \%$ include $28.5 \%$ caprylic acid, $20 \%$ capric acid, $1 \%$ lauric acid and $0.5 \%$ caproic acid [76]. The long-chain fatty acids contained in Lipofundin ${ }^{\circledR}$ MCT/LCT 20\% include $29.1 \%$ linoleic acid, $11 \%$ oleic acid, $7.4 \%$ palmitic acid, $4.5 \%$ alpha-linolenic acid and $2 \%$ stearic acid [76]. SMOFlipid ${ }^{\circledR} \quad 20 \%$ includes $30 \%$ soybean oil, $30 \%$ coconut oil, $25 \%$ olive oil and $15 \%$ fish oil [76]. ClinOleic ${ }^{\circledR} 20 \%$ includes $20 \%$ soybean oil and $80 \%$ olive oil [1].

The binding capacity of Intralipid ${ }^{\circledR}$ to bupivacaine in the buffer solution is 2.5-fold higher than that of Medialipid $\AA$ [27]. Conversely, Lipofundin ${ }^{\circledR}$ MCT/LCT absorbs more bupivacaine from serum than does Intralipid ${ }^{\circledR}$ [28]. A previous study showed that Intralipid $\AA 20 \%$ and ClinOleic ${ }^{\circledR}$ $20 \%$ did not significantly differ in the magnitude of the reduction in bupivacaine concentration (induced by lipid emulsion) in the buffer [78]. Lipofundin ${ }^{\circledR}$ MCT/LCT produced a greater reversal of toxic-dose bupivacaine-induced vasodilation in isolated rat aortas than Intralipid ${ }^{\circledR}$ [30]. These different results may be attributed to differences in the solution (buffer solution versus serum) and method (binding study versus tension study) and the small sample size $[27,28,30,78]$. Intralipid® ${ }^{\circledR}$ resulted in fewer incidences of recurrent asystole and lower myocardial bupivacaine concentrations from bupivacaineinduced cardiac arrest in rats than lipid emulsion with a mixture of $50 \%$ medium-chain and $50 \%$ long-chain triglycerides [79]. Pretreatment with the propofol contained in Intralipid ${ }^{\circledR}$ increased the time required to produce bupivacaine-induced cardiac arrest in rats compared with pretreatment with the propofol contained in Medialipid( ${ }^{\circledR}$ [80]. Intralipid® ${ }^{\circledR}(1 \%)$ attenuates the blockade of cardiac sodium channels induced by bupivacaine, whereas Lipofundin ${ }^{\circledR}$ MCT/LCT (1\%) does not significantly alter it [73]. As recommended by the American Society of Regional Anesthesia and Pain Medicine, these results suggest that Intralipid® is better than lipid emulsion with a mixture of medium-chain and long-chain fatty acids 
in lipid emulsion-mediated resuscitation of bupivacaine toxicity [73,79-81]. Lipid emulsion with $100 \%$ long-chain triglycerides alone and lipid emulsion with a mixture of $50 \%$ medium-chain triglycerides and $50 \%$ long-chain triglycerides did not significantly differ in the reversal of cardiac electrophysiological alterations (for example, prolongation of the His-ventricle interval and QRS period) induced by bupivacaine in anesthetized and mechanically ventilated piglets [82]. Intralipid ${ }^{\circledR}$ and Lipofundin ${ }^{\circledR}$ MCT/LCT equally reversed toxic doses of levobupivacaine-induced vasodilation of isolated endotheliumdenuded rat aortas [66]. Other types of lipid emulsions, including Lipofundin ${ }^{\circledR}$ MCT/LCT, Medialipid ${ }^{\circledR}$ and SMOFlipid ${ }^{\circledR}$ (other than Intralipid $\left.{ }^{\circledR}\right)$, can reportedly treat toxicity induced by local anesthetic and other drugs [83-85]. Thus, as the effects of two lipid emulsions on the recovery from toxic doses of bupivacaine-induced cardiovascular collapse are controversial, it remains to be determined which type of fatty acid (long-chain versus medium-chain) is more beneficial in a laboratory setting at simulating clinical cardiovascular collapse induced by toxic doses of local anesthetics.

\section{The effect of epinephrine on lipid emulsion-mediated resuscitation}

Lipid emulsion treatment after epinephrine (100 $\mu \mathrm{g} / \mathrm{kg})$ and vasopressin $(1.5 \mathrm{U} / \mathrm{kg})$ administration following chest compression did not improve the extent of return of spontaneous circulation (ROSC) compared with normal saline after bupivacaineinduced cardiac arrest in swine [86]. Moreover, compared with lipid emulsion alone, high doses of epinephrine $(>10 \mu \mathrm{g} / \mathrm{kg})$ combined with lipid emulsion inhibited sustained ROSC in bupivacaineinduced cardiac arrest of rats and caused hyperlactatemia and severe acidosis [87]. These results suggest that high doses of epinephrine and vasopressin inhibit lipid emulsion-mediated resuscitation because high-dose epinephrine causes acidosis and less sustained ROSC [86-88]. Epinephrine administration immediately after lipid emulsionmediated resuscitation or after the bolus administration of lipid emulsion in a bupivacaineinduced cardiac arrest rat model decreased the lung injury caused by epinephrine and improved survival compared with epinephrine administration before the bolus administration of lipid emulsion [89,90]. Lipid emulsion alone $(4 \mathrm{ml} / \mathrm{kg})$ followed by continuous infusion of lipid emulsion $(0.25 \mathrm{ml} / \mathrm{kg} / \mathrm{min})$, combined treatment with lipid emulsion $(4 \mathrm{ml} / \mathrm{kg}$ followed by $0.25 \mathrm{ml} / \mathrm{kg} / \mathrm{min})$ and epinephrine $(10$ $\mu \mathrm{g} / \mathrm{kg}$, repeated every $3 \mathrm{~min}$ ) or epinephrine (10 $\mu \mathrm{g} / \mathrm{kg}$, repeated every $3 \mathrm{~min}$ ) alone equally improved ROSC following levobupivacaine-induced cardiovascular collapse in newborn piglets compared with controls [91]. For arrhythmia after ROSC, treatment with epinephrine alone or lipid emulsion plus epinephrine increased the number of arrhythmia events compared with lipid emulsion alone [91]. This result suggests that high doses $(10 \mu \mathrm{g} / \mathrm{kg})$ of epinephrine, with or without lipid emulsion, induce cardiac arrhythmia [91]. In cardiac arrest induced by toxic doses of local anesthetics, epinephrine improves coronary perfusion due to increased systemic vascular resistance and inotropic effects, which may contribute to the lipid emulsion-mediated removal of bupivacaine from the myocardium [92]. Epinephrine used in resuscitation exaggerates the arrhythmia caused by bupivacaine and induces lung injury [92]. Compared with lipid emulsion $(2 \%)$ or epinephrine $(0.15 \mu \mathrm{g} / \mathrm{kg})$ alone, combined treatment with lipid emulsion (Intralipid ${ }^{\circledR} 2 \%$ ) and epinephrine (0.15 $\mu \mathrm{g} / \mathrm{kg}$ ) resulted in better recovery of the rate pressure product (cardiac function) from bupivacaine-induced cardiac asystole in isolated rat hearts using the non-recirculating Langendorff preparation [93]. Furthermore, Intralipid® $(5 \mathrm{ml} / \mathrm{kg}$ followed by 0.5 $\mathrm{ml} / \mathrm{kg} / \mathrm{min}$ ) improved the rate pressure product and metabolic parameters $(\mathrm{pH}$, lactate level, and central venous oxygen saturation) in bupivacaine-induced cardiac arrest in rats compared with epinephrine alone $(30 \mu \mathrm{g} / \mathrm{kg})$ [94]. Thus, these previous studies suggest that a low dose of epinephrine may be beneficial in the lipid emulsion-mediated resuscitation of cardiac arrest induced by bupivacaine, as recommended by the American Society of Regional Anesthesia and Pain Medicine [81,92-94]. Combined treatment with epinephrine $(45,45$ and $200 \mu \mathrm{g} / \mathrm{kg}$ ) and vasopressin $(0.4,0.4$ and $0.8 \mathrm{U} / \mathrm{kg}$ ) administered every $5 \mathrm{~min}$ improved survival following cardiac arrest induced by bupivacaine followed by hypoxia in a porcine model compared with lipid emulsion

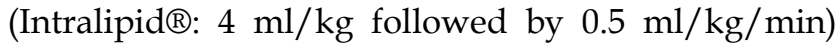
alone [95]. In contrast, Weinberg et al. reported that lipid emulsion (Intralipid ${ }^{\circledR}$ ) enhanced survival of bupivacaine-induced circulatory arrest in dogs compared with saline [14]. This difference may be due to the different experimental methods (toxic dose of bupivacaine followed by hypoxia versus toxic dose of bupivacaine alone) and species (pig versus dog) employed. Hypoxia and acidosis potentiate local anesthetic toxicity [81]. Thus, as recommended by the American Society of Regional Anesthesia and Pain Medicine, hypoxia and acidosis at the early stages of local anesthetic toxicity should be prevented by supplying the airway with $100 \%$ oxygen [81]. The different results regarding the addition of epinephrine 
to the lipid emulsion used to treat cardiac arrest caused by local anesthetic systemic toxicity may be attributed to the experimental method (without hypoxia versus with hypoxia), dosage of epinephrine, species (rats, dogs and pigs) and sample size. Because of the conflicting results regarding the effect of epinephrine on the lipid emulsion-mediated resuscitation of local anesthetic systemic toxicity, further studies are needed to investigate the effects of epinephrine (dosage, timing and method of administration) on lipid emulsion-mediated resuscitation in a laboratory setting, similar to the clinical cardiovascular collapse induced by toxic doses of local anesthetics.

\section{Recommended lipid emulsion treatment of local anesthetic systemic toxicity}

If symptoms and signs of local anesthetic systemic toxicity, including dizziness, agitation, tachycardia and hypertension, are detected, the airway should be maintained to avoid hypoxia and acidosis because hypoxia and acidosis exaggerate local anesthetic toxicity [81]. Seizures should be treated with benzodiazepine (midazolam, 1 to $5 \mathrm{mg}$ ) [81]. If seizures are not controlled with benzodiazepine, a small dose of succinylcholine should be administered to reduce the risk of acidosis and hypoxia [81]. Acidosis and hypoxia observed during seizure may be due to enhanced lactate production, oxygen consumption and inadequate respiration [96]. Lipid emulsion can be used to treat the incipient stage of cardiovascular depression induced by local anesthetic systemic toxicity before the development of cardiac arrest due to local anesthetic toxicity $[81,83,97,98]$. If cardiac arrest is caused by local anesthetic systemic toxicity, advanced cardiac life support should be administered [81]. If epinephrine is used to treat cardiac arrest induced by toxic doses of local anesthetic, a small dose (10 to 100 $\mu \mathrm{g}$ ) of epinephrine is preferred [81]. Vasopressin is not recommended [81]. If ventricular arrhythmia occurs, amiodarone is administered; treatment using local anesthetics (lidocaine or procainamide) is not recommended [81]. The following lipid emulsion treatment for local anesthetic systemic toxicity is recommended by the American Society of Regional Anesthesia and Pain Medicine and Association of Anaesthetists of Great Britain and Ireland: 1) a bolus administration (1.5 ml/ $\mathrm{kg}$ based on lean body mass) of Intralipid® $20 \%$ over $1 \mathrm{~min}$, followed by a continuous infusion $(0.25 \mathrm{ml} / \mathrm{kg} / \mathrm{min}$ based on lean body mass) of Intralipid ${ }^{\circledR} 20 \%$, which should be continuously infused for at least $10 \mathrm{~min}$ after hemodynamic stability is obtained; 2) if hemodynamic stability is not obtained, a maximum of two repeated boluses of Intralipid ${ }^{\circledR} 20 \% \quad(1.5 \mathrm{ml} / \mathrm{kg})$ followed by continuous infusion of Intralipid® $20 \%$ with an increased dosage $(0.5 \mathrm{ml} / \mathrm{kg} / \mathrm{min})$ should be considered; and 3) Intralipid ${ }^{\circledR} 20 \%$ at approximately $10 \mathrm{ml} / \mathrm{kg}$ for $30 \mathrm{~min}$ is the recommended upper limit of the initial dosage [81,99]. For example, a rough estimate of the initial dosing regimen of Intralipid ${ }^{\circledR}$ $20 \%$ in a patient with a $70 \mathrm{~kg}$ body weight, which is easily remembered, is as follows: intravenous bolus administration $(100 \mathrm{ml})$ of Intralipid ${ }^{\circledR} 20 \%$ over $1 \mathrm{~min}$, followed by continuous infusion $(1000 \mathrm{ml} / \mathrm{hr})$ of Intralipid® 20\% [99]. Cardiopulmonary resuscitation and oxygenation should be maintained during lipid emulsion infusion in cases of cardiac arrest due to local anesthetic toxicity. If the patient does not respond to the lipid emulsion and vasopressor treatment, cardiopulmonary bypass should be initiated $[81,99]$.

The early but less frequent adverse effects of Intralipid ${ }^{\circledR}$ include hyperlipidemia, dyspnea, allergic reaction, hypercoagulability and irritation [100]. The delayed less frequent adverse effects of Intralipid ${ }^{\circledR}$ include hepatomegaly, thrombocytopenia, splenomegaly, and transient elevation of liver function test values [100]. The side effects of lipid emulsion treatment used as parenteral nutrition include infection, hyperlipidemia, decreased immune response, acute pancreatitis, interference with laboratory examinations using serum, and parenteral nutritionassociated liver disease [1,101]. Infection and hyperlipidemia may be associated with impaired reticuloendothelial function and lead to impaired pulmonary gas exchange, respectively [1]. However, the side effects induced by lipid emulsion infusion are mild and transient for a short-term infusion compared with the fatal complications, such as cardiovascular depression and cardiac arrest, induced by toxic doses of local anesthetic, which require immediate lipid emulsion treatment [4].

\section{Conclusion}

Lipid emulsion administration is effective in treating cardiovascular collapse and central nervous system symptoms caused by local anesthetic toxicity, including that of bupivacaine, levobupivacaine, ropivacaine, lidocaine and mepivacaine. Moreover, lipid emulsion may be effective in alleviating intractable cardiovascular collapse induced by toxic doses of non-local anesthetic drugs, including calcium channel blockers (verapamil), tricyclic antidepressants (amitriptyline) and beta-blockers, which is reflected in case reports of successful lipid emulsion treatment for the toxicity caused by non-local anesthetic drugs $[2,3,102]$. 


\section{Abbreviations}

AMPK: 5-Adenosine monophosphate-activated protein kinase; ATP: Adenosine triphosphate; HEK: Human embryonic kidney; ROSC: Return of spontaneous circulation; GSK-3 $\beta$ : Glycogen synthase kinase-3ß; PI3K: Phosphoinositide 3-kinase.

\section{Acknowledgements}

This research was supported by Basic Science Research Program through the National Research Foundation of Korea (NRF) funded by the Ministry of Education (NRF-2016R1D1A1B03930451). This work was supported by Biomedical Research Institute Fund (GNUHBRIF-2017-0010) from the Gyeongsang National University Hospital.

\section{Competing Interests}

The authors have declared that no competing interest exists.

\section{References}

1. Raman M, Almutairdi A, Mulesa L, Alberda C, Beattie C, Gramlich L. Parenteral nutrition and lipids. Nutrients. 2017; Doi: 10.3390/nu9040388.

2. Cao D, Heard K, Foran M, Koyfman A. Intravenous lipid emulsion in the emergency department: a systematic review of recent literature. J Emerg Med. 2015; 48:387-97.

3. Waring WS. Intravenous lipid administration for drug-induced toxicity: a critical review of the existing data. Expert Rev Clin Pharmacol. 2012; 5:437-44.

4. Felice K, Schumann H. Intravenous lipid emulsion for local anesthetic toxicity: a review of the literature. J Med Toxicol. 2008; 4:184-91.

5. Fettiplace MR, McCabe DJ. Lipid emulsion improves survival in animal models of local anesthetic toxicity: a meta-analysis. Clin Toxicol (Phila). 2017; 55:617-23.

6. Weinberg GL. Lipid emulsion infusion: resuscitation for local anesthetic and other drug overdose. Anesthesiology. 2012; 117:180-7.

7. Weinberg GL, Laurito CE, Geldner P, Pygon BH, Burton BK. Malignant ventricular dysrhythmias in a patient with isovaleric acidemia receiving general and local anesthesia for suction lipectomy. J Clin Anesth. 1997; 9:668-70.

8. Wong GK, Crawford MW. Carnitine deficiency increases susceptibility to bupivacaine-induced cardiotoxicity in rats. Anesthesiology. 2011; 114:1417-24.

9. Gvozdjakova A. Mitochondrial medicine. Mitochondrial metabolism, diagnosis, disease and therapy. Netherland: Springer. 2008.

10. Weinberg GL, Palmer JW, VadeBoncouer TR, Zuechner MB, Edelman G, Hoppel CL. Bupivacaine inhibits acylcarnitine exchange in cardiac mitochondria. Anesthesiology. 2000; 92:523-8.

11. Wong GK, Pehora C, Crawford MW. L-carnitine reduces susceptibility to bupivacaine-induced cardiotoxicity: an experimental study in rats. Can J Anaesth. 2017; 64:270-9.

12. Wong GK, Joo DT, McDonnell C. Lipid resuscitation in a carnitine deficient child following intravascular migration of an epidural catheter. Anaesthesia. 2010; 65:192-5.

13. Weinberg GL, VadeBoncouer T, Ramaraju GA, Garcia-Amaro MF, Cwik MJ. Pretreatment or resuscitation with a lipid infusion shifts the dose-response to bupivacaine-induced asystole in rats. Anesthesiology. 1998; 88:1071-5.

14. Weinberg G, Ripper R, Feinstein DL, Hoffman W. Lipid emulsion infusion rescues dogs from bupivacaine-induced cardiac toxicity. Reg Anesth Pain Med. 2003; 28:198-202.

15. Oda Y, Ikeda Y. Effect of lipid emulsion on the central nervous system and cardiac toxicity of bupivacaine and levobupivacaine in awake rats. J Anesth. 2013; 27:500-4

16. Rosenblatt MA, Abel M, Fischer GW, Itzkovich CJ, Eisenkraft JB. Successful use of a $20 \%$ lipid emulsion to resuscitate a patient after a presumed bupivacaine-related cardiac arrest. Anesthesiology. 2006; 105:217-8.

17. Sirianni AJ, Osterhoudt KC, Calello DP, Muller AA, Waterhouse MR, Goodkin MB, et al. Use of lipid emulsion in the resuscitation of a patient with prolonged cardiovascular collapse after overdose of bupropion and lamotrigine. Ann Emerg Med. 2008; 51:412-5.

18. Weinberg GL, Ripper R, Murphy P, Edelman LB, Hoffman W, Strichartz G, et al. Lipid infusion accelerates removal of bupivacaine and recovery from bupivacaine toxicity in the isolated rat heart. Reg Anesth Pain Med. 2006; 31:296-303.

19. Chen Y, Xia Y, Liu L, Shi T, Shi K, Wang Q, et al. Lipid emulsion reverses bupivacaine-induced asystole in isolated rat hearts: concentration-response and time-response relationships. Anesthesiology. 2010; 113:1320-5.

20. Zausig YA, Zink W, Keil M, Sinner B, Barwing J, Wiese CH, et al. Lipid emulsion improves recovery from bupivacaine-induced cardiac arrest, but not from ropivacaine- or mepivacaine-induced cardiac arrest. Anesth Analg. 2009; 109:1323-6.

21. Aumeier C, Kasdorf B, Gruber M, Busse H, Wiese CH, Zink W, Graf BM, et al. Lipid emulsion pretreatment has different effects on mepivacaine and bupivacaine cardiac toxicity in an isolated rat heart model. Br J Anaesth. 2014; 112:735-41.

22. Warren L, Weinberg G. Lipid emulsion and recovery from local anesthetic-induced "cardiac arrest": misleading interpretations. Anesth Analg. 2010; 110:1750-1

23. Strichartz GR, Sanchez V, Arthur GR, Chafetz R, Martin D. Fundamental properties of local anesthetics. II. Measured octanol:buffer partition coefficients and pKa values of clinically used drugs. Anesth Analg. 1990; 71:158-70.

24. Park WK, Kim HS, Kim SH, Jung JR, Lynch C 3rd, Min NH. Intralipid restoration of myocardial contractions following bupivacaine-induced asystole: concentration- and time-dependence in vitro. Anesth Analg. 2017; 125:91-100.

25. French D, Smollin C, Ruan W, Wong A, Drasner K, Wu AH. Partition constant and volume of distribution as predictors of clinical efficacy of lipid rescue for toxicological emergencies. Clin Toxicol (Phila). 2011; 49:801-9.

26. Wagner M, Zausig YA, Ruf S, Rudakova E, Gruber M, Graf BM, et al. Lipid rescue reverses the bupivacaine-induced block of the fast $\mathrm{Na}+$ current (INa) in cardiomyocytes of the rat left ventricle. Anesthesiology. 2014; 120:724-36.

27. Mazoit JX, Le Guen R, Beloeil H, Benhamou D. Binding of long-lasting local anesthetics to lipid emulsions. Anesthesiology. 2009; 110:380-6.

28. Ruan W, French D, Wong A, Drasner K, Wu AH. A mixed (long- and medium-chain) triglyceride lipid emulsion extracts local anesthetic from human serum in vitro more effectively than a long-chain emulsion. Anesthesiology. 2012; 116:334-9.

29. Ok SH, Lee SH, Kwon SC, Choi MH, Shin IW, Kang S, et al. A Lipid emulsion reverses toxic-dose bupivacaine-induced vasodilation during tyrosine phosphorylation-evoked contraction in isolated rat aortae. Int J Mol Sci. 2017; Doi: 10.3390/ijms18020394

30. Ok SH, Han JY, Lee SH, Shin IW, Lee HK, Chung YK, et al. Lipid emulsion-mediated reversal of toxic-dose aminoamide local anesthetic-induced vasodilation in isolated rat aorta. Korean J Anesthesiol. 2013; 64:353-9.

31. Ok SH, Sohn JT, Baik JS, Kim JG, Park SS, Sung HJ, et al. Lipid emulsion reverses levobupivacaine-induced responses in isolated rat aortic vessels. Anesthesiology. 2011; 114:293-301.

32. Cho $\mathrm{H}, \mathrm{Ok} \mathrm{SH}_{\text {, Kwon }} \mathrm{SC}$, Lee $\mathrm{SH}$, Baik J, Kang $\mathrm{S}$, et al Lipid emulsion inhibits vasodilation induced by a toxic dose of bupivacaine by suppressing bupivacaine-induced PKC and CPI-17 dephosphorylation but has no effect on vasodilation induced by a toxic dose of mepivacaine. Korean J Pain. 2016; 29:229-38.

33. Ok SH, Byon HJ, Kwon SC, Park J, Lee Y, Hwang Y, et al. Lipid emulsion inhibits vasodilation induced by a toxic dose of bupivacaine via attenuated dephosphorylation of myosin phosphatase target subunit 1 in isolated rat aorta. Int J Med Sci. 2015; 12:958-67.

34. Lee SH, Sung HJ, Ok SH, Yu J, Choi MJ, Lim JS, et al. Lipid emulsions enhance the norepinephrine-mediated reversal of local anesthetic-induced vasodilation at toxic doses. Yonsei Med J. 2013; 54:1524-32

35. Ok SH, Yu J, Lee Y, Cho H, Shin IW, Sohn JT. Lipid emulsion attenuates apoptosis induced by a toxic dose of bupivacaine in $\mathrm{H} 9 \mathrm{c} 2$ rat cardiomyoblast cells. Hum Exp Toxicol. 2016; 35:929-37.

36. Kuo I, Akpa BS. Validity of the lipid sink as a mechanism for the reversal of local anesthetic systemic toxicity: a physiologically based pharmacokinetic model study. Anesthesiology. 2013; 118:1350-61

37. Litonius E, Tarkkila P, Neuvonen PJ, Rosenberg PH. Effect of intravenous lipid emulsion on bupivacaine plasma concentration in humans. Anaesthesia. 2012; 67:600-5.

38. Shi K, Xia Y, Wang Q, Wu Y, Dong X, Chen C, et al. The effect of lipid emulsion on pharmacokinetics and tissue distribution of bupivacaine in rats. Anesth Analg. 2013; 116:804-9.

39. Fettiplace MR, Lis K, Ripper R, Kowal K, Pichurko A, Vitello D, et al. Multi-modal contributions to detoxification of acute pharmacotoxicity by a triglyceride micro-emulsion. J Control Release. 2015; 198:62-70.

40. Heinonen JA, Litonius E, Salmi T, Haasio J, Tarkkila P, Backman JT, et al. Intravenous lipid emulsion given to volunteers does not affect symptoms of lidocaine brain toxicity. Basic Clin Pharmacol Toxicol. 2015; 116:378-83.

41. Dureau P, Charbit B, Nicolas N, Benhamou D, Mazoit JX. Effect of intralipid ${ }^{\circledR}$ on the dose of ropivacaine or levobupivacaine tolerated by volunteers: a clinical and pharmacokinetic study. Anesthesiology. 2016; 125:474-83.

42. Kazemi A, Harvey M, Cave G, Lahner D. The effect of lipid emulsion on depth of anaesthesia following thiopental administration to rabbits. Anaesthesia. 2011; 66:373- 8 
43. Fettiplace MR, Weinberg G. Past, present, and future of lipid resuscitation therapy. JPEN J Parenter Enteral Nutr. 2015; 39:72S-83S.

44. Shih YH, Chen $\mathrm{CH}$, Wang YM, Liu K. Successful reversal of bupivacaine and lidocaine-induced severe junctional bradycardia by lipid emulsion following infraclavicular brachial plexus block in a uremic patient. Acta Anaesthesiol Taiwan. 2011; 49:72-4

45. Litz RJ, Popp M, Stehr SN, Koch T. Successful resuscitation of a patient with ropivacaine-induced asystole after axillary plexus block using lipid infusion. Anaesthesia. 2006; 61:800-1.

46. Dix SK, Rosner GF, Nayar M, Harris JJ, Guglin ME, Winterfield JR, et al. Intractable cardiac arrest due to lidocaine toxicity successfully resuscitated with lipid emulsion. Crit Care Med. 2011; 39:872-4

47. Litz RJ, Roessel T, Heller AR, Stehr SN. Reversal of central nervous system and cardiac toxicity after local anesthetic intoxication by lipid emulsion injection. Anesth Analg. 2008; 106:1575-7.

48. Sonsino DH, Fischler M. Immediate intravenous lipid infusion in the successful resuscitation of ropivacaine-induced cardiac arrest after infraclavicular brachial plexus block. Reg Anesth Pain Med. 2009; 34:276-7.

49. Partownavid P, Umar S, Li J, Rahman S, Eghbali M. Fatty-acid oxidation and calcium homeostasis are involved in the rescue of bupivacaine-induced cardiotoxicity by lipid emulsion in rats. Crit Care Med. 2012; 40:2431-7.

50. Eledjam JJ, de La Coussaye JE, Brugada J, Bassoul B, Gagnol JP, Fabregat JR, et al. In vitro study on mechanisms of bupivacaine-induced depression of myocardial contractility. Anesth Analg. 1989; 69:732-5.

51. Yang L, Bai Z, Lv D, Liu H, Li X, Chen X. Rescue effect of lipid emulsion on bupivacaine-induced cardiac toxicity in cardiomyocytes. Mol Med Rep. 2015; 12:3739-47.

52. Chen Z, Jin Z, Xia Y, Zhao S, Xu X, Papadimos TJ, et al. The protective effect of lipid emulsion in preventing bupivacaine-induced mitochondrial injury and apoptosis of H9C2 cardiomyocytes. Drug Deliv. 2017; 24:430-6.

53. Heinonen JA, Schramko AA, Skrifvars MB, Litonius E, Backman JT, Mervaala $\mathrm{E}$, et al. The effects of intravenous lipid emulsion on hemodynamic recovery and myocardial cell mitochondrial function after bupivacaine toxicity in anesthetized pigs. Hum Exp Toxicol. 2017; 36:365-75.

54. Fettiplace MR, Ripper R, Lis K, Lin B, Lang J, Zider B, et al. Rapid cardiotonic effects of lipid emulsion infusion*. Crit Care Med. 2013; 41:e156-62.

55. Park J, Kim YA, Han JY, Jin S, Ok SH, Sohn JT, et al. Lipofundin® MCT/LCT $20 \%$ increase left ventricular systolic pressure in an ex vivo rat heart model via increase of intracellular calcium level. Korean J Anesthesiol. 2016; 69:57-62.

56. Stehr SN, Ziegeler JC, Pexa A, Oertel R, Deussen A, Koch T, et al. The effects of lipid infusion on myocardial function and bioenergetics in 1-bupivacaine toxicity in the isolated rat heart. Anesth Analg. 2007; 104:186-92

57. Rahman S, Li J, Bopassa JC, Umar S, Iorga A, Partownavid P, et al. Phosphorylation of GSK-3 $\beta$ mediates intralipid-induced cardioprotection against ischemia/reperfusion injury. Anesthesiology. 2011; 115:242-53.

58. Partownavid P, Sharma S, Li J, Umar S, Rahman S, Eghbali M. Involvement of opioid receptors in the lipid rescue of bupivacaine-induced cardiotoxicity. Anesth Analg. 2015; 121:340-7.

59. Fettiplace MR, Kowal K, Ripper R, Young A, Lis K, Rubinstein I, et al. Insulin signaling in bupivacaine-induced cardiac toxicity: sensitization during recovery and potentiation by lipid emulsion. Anesthesiology. 2016; 124:428-42

60. Lv D, Bai Z, Yang L, Li X, Chen X. Lipid emulsion reverses bupivacaine-induced apoptosis of h9c2 cardiomyocytes: PI3K/Akt/GSK-3 $\beta$ signaling pathway. Environ Toxicol Pharmacol. 2016; 42:85-91.

61. Ok SH, Choi MH, Shin IW, Lee SH, Kang S, Oh J, et al. Lipid Emulsion Inhibits Apoptosis Induced by a Toxic Dose of Verapamil via the Delta-Opioid Receptor in H9c2 Rat Cardiomyoblasts. Cardiovasc Toxicol. 2017; 17:344-54.

62. Ok SH, Lee SH, Yu J, Park J, Shin IW, Lee Y, et al. Lipid emulsion attenuates acetylcholine-induced relaxation in isolated rat aorta. Biomed Res Int. 2015; Doi: $10.1155 / 2015 / 871545$.

63. Ok SH, Han JY, Sung HJ, Yang SM, Park J, Kwon SC, et al. Ropivacaine-induced contraction is attenuated by both endothelial nitric oxide and voltage-dependent potassium channels in isolated rat aortae. Biomed Res Int. 2013; Doi: 10.1155/2013/565271.

64. Sung HJ, Choi MJ, Ok SH, Lee SH, Hwang IJ, Kim HS, et al. Mepivacaine-induced contraction is attenuated by endothelial nitric oxide release in isolated rat aorta. Can J Physiol Pharmacol. 2012; 90:863-72.

65. Choi YS, Jeong YS, Ok SH, Shin IW, Lee SH, Park JY, et al. The direct effect of levobupivacaine in isolated rat aorta involves lipoxygenase pathway activation and endothelial nitric oxide release. Anesth Analg. 2010; 110:341-9.

66. Ok SH, Park CS, Kim HJ, Lee SH, Choi BH, Eun SY, et al. Effect of two lipid emulsions on reversing high-dose levobupivacaine-induced reduced vasoconstriction in the rat aortas. Cardiovasc Toxicol. 2013; 13:370-80.

67. Shin IW, Hah YS, Kim C, Park J, Shin H, Park KE, et al. Systemic blockage of nitric oxide synthase by L-NAME increases left ventricular systolic pressure, which is not augmented further by Intralipid ${ }^{\circledR}$. Int J Biol Sci 2014; 10:367-76.

68. Stojiljkovic MP, Zhang D, Lopes HF, Lee CG, Goodfriend TL, Egan BM. Hemodynamic effects of lipids in humans. Am J Physiol Regul Integr Comp Physiol. 2001; 280(R):1674-9.

69. Van de Velde M, Wouters PF, Rolf N, Van Aken H, Vandermeersch E. Comparative hemodynamic effects of three different parenterally administered lipid emulsions in conscious dogs. Crit Care Med. 1998; 26:132-7

70. Ok SH, Kim WH, Yu J, Lee Y, Choi MJ, Lim DH, et al. Effects of acidification and alkalinization on the lipid emulsion-mediated reversal of toxic dose levobupivacaine-induced vasodilation in the isolated rat aorta. Int J Med Sci. 2016; 13:68-76.

71. Coyle DE, Denson DD, Thompson GA, Myers JA, Arthur GR, Bridenbaugh $\mathrm{PO}$. The influence of lactic acid on the serum protein binding of bupivacaine: species differences. Anesthesiology. 1984; 61:127-33.

72. Becker DE, Reed KL. Essentials of local anesthetic pharmacology. Anesth Prog. 2006; 53:98-108

73. Nadrowitz F, Stoetzer C, Foadi N, Ahrens J, Wegner F, Lampert A, et al. The distinct effects of lipid emulsions used for "lipid resuscitation" on gating and bupivacaine-induced inhibition of the cardiac sodium channel Nav1.5. Anesth Analg. 2013; 117:1101-8.

74. Mottram AR, Valdivia CR, Makielski JC. Fatty acids antagonize bupivacaine-induced I(Na) blockade. Clin Toxicol (Phila). 2011; 49:729-33.

75. Xiao YF, Ke Q, Wang SY, Auktor K, Yang Y, Wang GK, et al. Single point mutations affect fatty acid block of human myocardial sodium channel alpha subunit Na+ channels. Proc Natl Acad Sci USA. 2001; 98:3606-11.

76. Wanten GJ, Calder PC. Immune modulation by parenteral lipid emulsions. Am J Clin Nutr. 2007; 85:1171-84.

77. Mertes N, Grimm H, Fürst P, Stehle P. Safety and efficacy of a new parenteral lipid emulsion (SMOFlipid) in surgical patients: a randomized, double-blind, multicenter study. Ann Nutr Metab. 2006; 50:253-9.

78. Evans JA, Wallis SC, Dulhunty JM, Pang G. Binding of local anaesthetics to the lipid emulsion Clinoleic ${ }^{\mathrm{TM}}$ 20\%. Anaesth Intensive Care. 2013; 41:618-22.

79. Li Z, Xia Y, Dong X, Chen H, Xia F, Wang X, et al. Lipid resuscitation of bupivacaine toxicity: long-chain triglyceride emulsion provides benefits over long- and medium-chain triglyceride emulsion. Anesthesiology. 2011; 115:1219-28.

80. Yilmaz M, Celebi H, Akcali D, Gurel N. Pre-treatment of bupivacaine-induced cardiovascular depression using different lipid formulations of propofol. Acta Anaesthesiol Scand. 2014; 58:298-302.

81. Neal JM, Bernards CM, Butterworth JF 4th, Di Gregorio G, Drasner K, Hejtmanek MR, et al. ASRA practice advisory on local anesthetic systemic toxicity. Reg Anesth Pain Med. 2010; 35:152-61

82. Candela D, Louart G, Bousquet PJ, Muller L, Nguyen M, Boyer JC, et al. Reversal of bupivacaine-induced cardiac electrophysiologic changes by two lipid emulsions in anesthetized and mechanically ventilated piglets. Anesth Analg. 2010; 110:1473-9.

83. Charbonneau H, Marcou TA, Mazoit JX, Zetlaoui PJ, Benhamou D. Early use of lipid emulsion to treat incipient mepivacaine intoxication. Reg Anesth Pain Med. 2009; 34:277-8.

84. Gil HW, Park JS, Park SH, Hong SY. Effect of intravenous lipid emulsion in patients with acute glyphosate intoxication. Clin Toxicol (Phila). 2013; 51:767-71.

85. Zimmer C, Piepenbrink $\mathrm{K}$, Riest G, Peters J. [Cardiotoxic and neurotoxic effects after accidental intravascular bupivacaine administration. Therapy with lidocaine propofol and lipid emulsion]. Anaesthesist. 2007; 56:449-53.

86. Hicks SD, Salcido DD, Logue ES, Suffoletto BP, Empey PE, Poloyac SM, et al. Lipid emulsion combined with epinephrine and vasopressin does not improve survival in a swine model of bupivacaine-induced cardiac arrest. Anesthesiology. 2009; 111:138-46.

87. Hiller DB, Gregorio GD, Ripper R, Kelly K, Massad M, Edelman L, et al. Epinephrine impairs lipid resuscitation from bupivacaine overdose: a threshold effect. Anesthesiology. 2009; 111:498-505.

88. Krishnamoorthy V, Vavilala MS, Fettiplace MR, Weinberg G. Epinephrine for cardiac arrest: are we doing more harm than good? Anesthesiology. 2014; 120:792-4.

89. Luo M, Yun X, Chen C, Bao N, Feng X, Pan L, et al. Giving priority to lipid administration can reduce lung injury caused by epinephrine in bupivacaine-induced cardiac depression. Reg Anesth Pain Med. 2016; 41:469-76.

90. Jin Z, Xia Y, Xia F, Wu C, Chen Z, Nan F, et al. Epinephrine administration in lipid-based resuscitation in a rat model of bupivacaine-induced cardiac arrest: optimal timing. Reg Anesth Pain Med. 2015; 40:223-31.

91. de Queiroz Siqueira M, Chassard D, Musard H, Heilporn A, Cejka JC, Leveneur $\mathrm{O}$, et al. Resuscitation with lipid, epinephrine, or both in levobupivacaine-induced cardiac toxicity in newborn piglets. Br J Anaesth. 2014; 112:729-34.

92. Wolfe JW, Butterworth JF. Local anesthetic systemic toxicity: update on mechanisms and treatment. Curr Opin Anaesthesiol. 2011; 24:561-6.

93. Liu L, Xia Y, Chen Y, Wang Q, Shi T, Wang F, et al. The comparative effects of lipid, epinephrine, and their combination in the reversal of bupivacaine-induced asystole in the isolated rat heart. Anesth Analg. 2012; 114:886-93.

94. Weinberg GL, Di Gregorio G, Ripper R, Kelly K, Massad M, Edelman L, et al. Resuscitation with lipid versus epinephrine in a rat model of bupivacaine overdose. Anesthesiology. 2008; 108:907-13

95. Mayr VD, Mitterschiffthaler L, Neurauter A, Gritsch C, Wenzel V, Müller T, et al. A comparison of the combination of epinephrine and vasopressin with lipid emulsion in a porcine model of asphyxia cardiac arrest after intravenous injection of bupivacaine. Anesth Analg. 2008; 106:1566-71.

96. Rice SA, Fish KJ. Anesthetic toxicity. New York, USA: Raven Press. 1994. 
97. McCutchen T, Gerancher JC. Early intralipid therapy may have prevented bupivacaine-associated cardiac arrest. Reg Anesth Pain Med. 2008; 33:178-80.

98. Foxall G, McCahon R, Lamb J, Hardman JG, Bedforth NM.

Levobupivacaine-induced seizures and cardiovascular collapse treated with Intralipid. Anaesthesia 2007; 62:516-8.

99. AAGBI Safety Guideline. Management of severe local anaesthetic toxicity. 2010. https://www.aagbi.org/sites/default/files/la_toxicity_2010_0.pdf (accessed on 10th August 2017).

100. Intralipid $®$ [package insert] Uppsala, Sweden. Fresenius Kabi. 2015.

101. Watt P, Malik D, Dyson L. Gift of the glob--is it foolproof? Anaesthesia. 2009; 64:1031-3.

102. Ozcan MS, Weinberg G. Intravenous lipid emulsion for the treatment of drug toxicity. J Intensive Care Med. 2014; 29:59-70. 